(RESEARCH ARTICLE)

\title{
Determination of uptake rate of phosphorus and changes in COD and BOD during photoautotrophic cultivation of microalgae in sewage effluent
}

Anumudu Obinna Henry 1, ${ }^{*}$, Akaniro Ifunanya Rejoice 1, Ezeh Chukwuemeka Cornelius ${ }^{1}$, Koledowo Adenike Kafilat ${ }^{2}$, Oweredaba Christabel Iworah ${ }^{3}$, Ofonegbu Mercy Nkechi ${ }^{1}$ and Kwekowe Pretty Chinecherem ${ }^{1}$

${ }^{1}$ Department of Microbiology, University of Nigeria, Nsukka, Enugu State, Nigeria.

${ }^{2}$ Department of Microbiology, Obafemi Awolowo University, Ile-Ife, Osun State, Nigeria

${ }^{3}$ School of Science, Engineering and Environment, University of Salford, UK.

Publication history: Received on 06 November 2019; revised on 12 December 2019; accepted on 13 December 2019

Article DOI: https://doi.org/10.30574/wjarr.2019.4.2.0083

\begin{abstract}
Photosynthetic organisms like microalgae possess useful potentials such as nutrient uptake, biological oxygen demand (BOD) and chemical oxygen demand (COD) removal from wastewater which are crucial for wastewater treatment. This study was conducted to determine the rate of phosphorus uptake and changes in COD and BOD during microalgae cultivation in sewage effluent. Standard Methods for the Examination of Water and Wastewater were used to analyse the characteristics of the effluent samples (test), BG-11 medium (control) and also determine algal growth rates under continuous light illumination and constant aeration at varying temperatures. Results obtained showed that; removal efficiencies of Chlorella sp were higher in the test samples than control. Removal efficiencies for BOD, COD and PO43were $92.8 \%, 59.6 \%$ and $61.8 \%$ respectively for the test samples and $39.8 \%, 41.7 \%$ and $28.2 \%$ for the control. Also, Chlorella sp demonstrated better removal efficiencies at higher growth rates, exponential growth phase, constant aeration and temperature range between 25-30 ${ }^{\circ} \mathrm{C}$. Hence, microalgae, under controlled and optimal conditions can be efficient in removal of pollutants in wastewater (sewage effluent).
\end{abstract}

Keywords: BOD; Chlorella sp; COD; Phosphorus; Removal efficiency; Sewage effluent

\section{Introduction}

Wastewater contains quite a number of pollutants that have to be removed before its discharge into surface waters as the discharge of wastewater that is rich in nutrients can cause eutrophication which is a serious problem that occurs particularly in enclosed water bodies [1]. Eutrophication occurs when a dense bloom of algae grow in water due to presence of high concentrations of nitrogen and phosphorus, the main nutrients of concern[1]. This depletes the level of oxygen in the aquatic system leading to loss of aquatic lives. While conventional biological treatment such as activated sludge removes organic matter from wastewater, many other constituents such as pathogens, nutrients and heavy metals are not eliminated to a satisfactory level. Over the years, many modifications have been introduced to traditional treatment processes to improve performance. However, majority of such modifications come with some limitations such as high cost and increased complexity in its operation and maintenance [2,3]. Use of microalgae in wastewater treatment has been gaining attention due to their effective roles in the uptake of pollutants from the environmental wastes as well as their ability to produce valuable biomass that can be used in different industrial applications such as food processing, pharmaceuticals, organic fertilizer, animal feed, bio-fuel and biogas [4]. In wastewater treatment applications, for instance, microalgae can assimilate nutrients, uptake $\mathrm{CO}_{2}$, provide $\mathrm{O}_{2}$ for aerobic bacteria, and produce biomass that can be used to boost biogas generation from anaerobic digesters [5]. Microalgae require nutrients basically nitrogen and phosphorus which are found in wastewater to grow. Nitrogen is widely available in wastewater in many forms. However, microalgae can assimilate only the inorganic nitrogen. Phosphorus is the second essential nutrient

\footnotetext{
${ }^{*}$ Corresponding author

E-mail address: wisdomchibuenyim99@gmail.com
} 
which promotes algal growth in wastewater. The most important form of phosphorus for microalgae is orthophosphate $\mathrm{PO}_{4}{ }^{3-}$ that is utilized directly by microalgae. Microalgae cannot take other forms of phosphorus until they are hydrolyzed by extracellular enzymes to $\mathrm{PO}_{4}^{3-}[6,7]$, microalgae also require inorganic carbon sources such as $\mathrm{CO}_{2}$ while growing under phototrophic conditions, alternatively, under heterotrophic conditions, they use dissolved organic carbon such as acetate, sugar, and organic acids as a carbon source causing the concentration of chemical oxygen demand (COD) to decrease. BOD is determined by the ability of microorganisms to convert organic material to $\mathrm{CO}_{2}$ and water using the oxidizing power of molecular oxygen. Therefore, BOD can result in asphyxiation or death of aquatic life since it depletes the dissolved oxygen of receiving water, hence, its removal in wastewater treatment is paramount [7]. Different kinds of microalgae have been used in wastewater treatment but Chlorella and Scenedesmus are most commonly used since they have been reported to be more tolerant and adaptive and can survive under different wastewater physical and biochemical conditions [8]. Microalgae are being used in waste stabilization ponds (WSPs) and high rate algae ponds (HRAPs) for wastewater treatment and its overall performance in waste removal is satisfactory. Nevertheless, microalgae treatment presents certain limitations because it requires large surface area for treatment and long hydraulic retention times. Global warming and shortage in fossil fuels have been the driving forces for humans to investigate sources of renewable energy that could provide a better alternative to fossil fuels [9, 10]. According to [11], microalgae biomass is an attractive option not just for waste water treatment, but also bio-fuel production since it uses fewer chemicals and emits less $\mathrm{CO}_{2}$ due to its high oil content. Some researchers $[3,12,13]$ have studied algae as a phyco-remediating agent for wastewater, however, not much attention has been paid to the impacts of temperature and cultivation time on the efficiencies of COD, BOD and orthophosphate removal. Hence, the overall objective of this research was to determine the uptake rate of phosphorus and to evaluate the changes in COD and BOD of photoautotropic cultivation of Microalgae in sewage effluent at different temperature and cultivation periods.

\section{Material and methods}

\subsection{Study Area}

The samples (sewage effluents) for this research were obtained from the sewage treatment plant, University of Nigeria, Nsukka. Nsukka lies on latitude $6.86^{\circ} \mathrm{N}$ and longitude $7.39^{\circ} \mathrm{E}$ longitude and covers a total land mass of $1,810 \mathrm{~km}^{2}$.

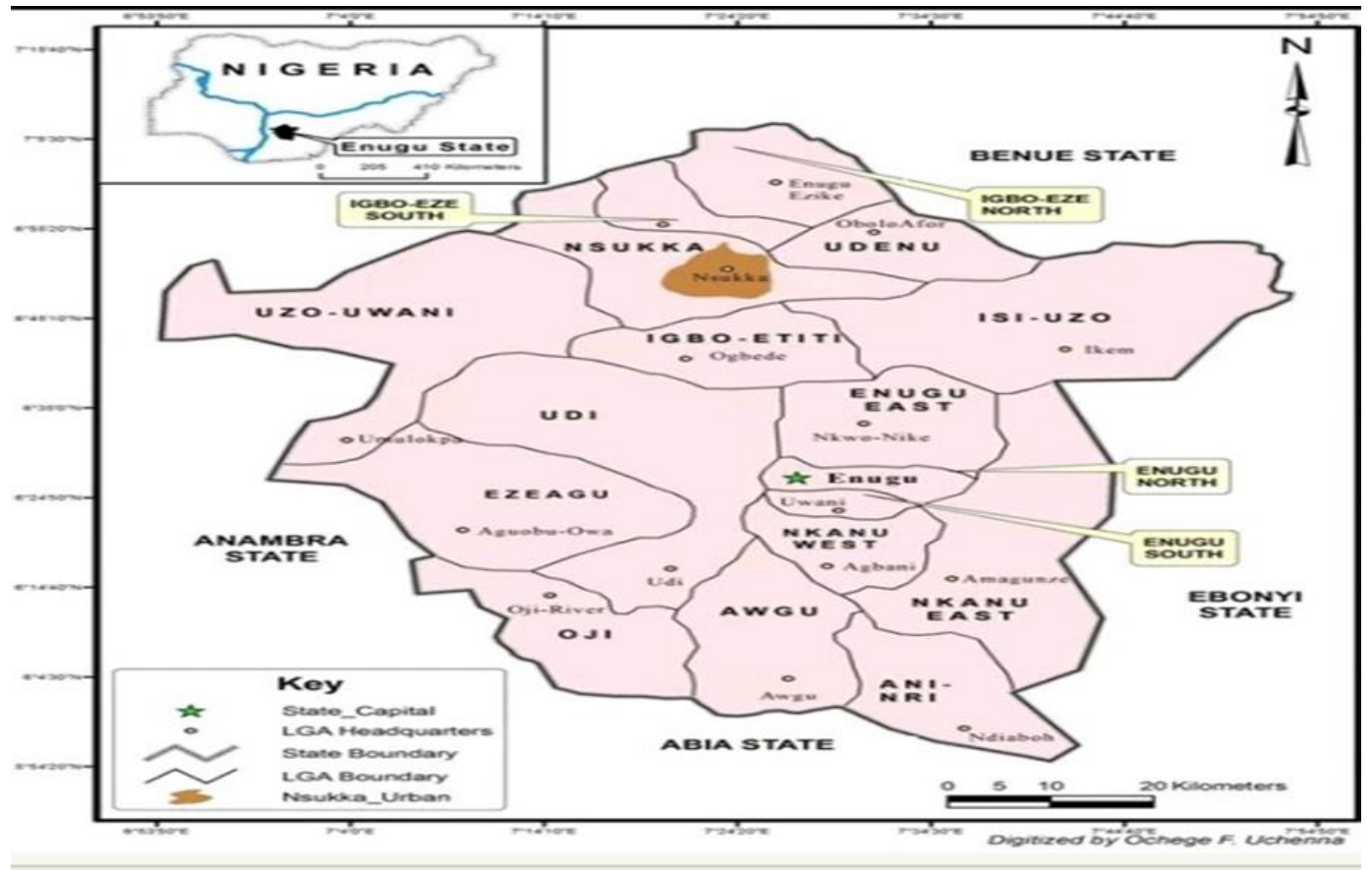

Figure 1 Map of Nsukka town (Adapted from Department of Geography Archives, UNN).

\subsection{Sample Collection}

Pretreated sewage sample was obtained at the terminal point of primary sewage treatment i.e. after sedimentation from University of Nigeria, Nsukka treatment plant. The sample was taken in 20 liter gallon and immediately transferred to 
the Water and Public Health Research Laboratory (WPHRL), Department of Microbiology, University of Nigeria, Nsukka where it was immediately subjected to sterilization to kill any faecal coliform present.

\subsection{Cultivation of Microalgae Species}

Sterilized sample (sewage effluent) was used as the broth medium for the cultivation and enrichment of the Microalgae. The broth culture was incubated for $48 \mathrm{hrs}$ at $25^{\circ} \mathrm{C}$ and under a fluorescent light source. After incubation, sterile petri dishes containing different concentrations of agar-agar medium $(2.4 \mathrm{~g} / 200 \mathrm{ml}$ and $2.0 \mathrm{~g} / 200 \mathrm{ml}$ of sterilized sewage effluent) were inoculated with the broth culture via a sterile wire loop, labeled as TP $2.4 \mathrm{~g}$ and TP $2.0 \mathrm{~g}$ respectively and incubated for 14 days under $25^{\circ} \mathrm{C}$ in the presence of light source. Cultivation of alga in $\mathrm{BG}-11$ medium $\left(\mathrm{NaNO}_{3}\right)$ was used as control.

\subsubsection{Pure Culture Isolation}

Three colonies were obtained after incubation in the plates having TP $2.4 \mathrm{~g}$ concentration while there was no growth in TP $2.0 \mathrm{~g}$ plates. The colonies were subcultured into 3 different agar-agar media, labeled TP- 1 , TP- 2 and TP- 3 and incubated under a light source for 4 days, the pure isolates were picked and inoculated into $8 \mathrm{ml}$ sterilized sewage effluent broth in 5 bijou bottles for enrichment.

\subsubsection{Identification of the Isolate}

A drop of the TP-1, TP-2 and TP-3isolates was placed on different glass slides, covered with cover slip and examined microscopically under X40 objective. The morphology of the algae seen was compared to the algae found in the Atlas of Microalgae.

\subsection{Batch reactor experimental set up}

Batch reactor experiments were conducted for 15 days at varying temperatures $\left(15-35^{\circ} \mathrm{C}\right)$. Four Bama bottles with 3 litres capacity were used for the set up. Aeration and agitation pump for $\mathrm{O}_{2}$ distribution and proper mixing were also supplied. Sewage effluent (1 litre) was poured into the $1^{\text {st }}$ bottle and inoculated with Chlorella sp., the 2nd bottle contained 1L of un-inoculated sewage effluent (TWR) while the 3rd had 1Lof BG-11 medium inoculated with Chlorella $s p$. (positive control).They were incubated at $30 \pm 2{ }^{\circ} \mathrm{C}$ with continuous light intensity $\left(1.42 \mathrm{mWcm}^{-2}\right)$ and constant agitation. Samples were taken on 3 days intervals for analyses of soluble or dissolved concentrations of COD, BOD, and Phosphorus $\left(\mathrm{PO}_{4}^{3-}\right)$.

\subsection{Wastewater Characterization}

\subsubsection{Wastewater Characterization}

Orthophosphate content: this was done as described by Standard Methods for the Examination of Water and Wastewater [14]. An aliquot of the solution (50 ml) was dropped into a flask, followed by the addition of few drops of phenolphthalein indicator. Upon pink colour development, strong acid solution was added drop wise. An aliquot of ammonium molybdate $(4 \mathrm{ml})$ was gently added into the mixture followed by subsequent addition of 4-5 drops of stannous chloride with through mixing. Samples were left unshaken for 10 minutes at room temperature for colour development. The absorbance was measured at $640 \mathrm{~nm}$.

\subsubsection{Biochemical Oxygen Demand}

HACH Method 8000 method was used [15] and BOD was measured as oxygen difference between the initial sample and after incubation for 5 days at $20^{\circ} \mathrm{C}$.

\subsubsection{Chemical Oxygen Demand (COD)}

COD was also analyzed according to HACH Method 8000 [15]. The samples were heated for two hours with sulfuric acid and a strong oxidizing agent, potassium dichromate. All oxidizable organic compounds reacted and reduced the dichromate ion (Cr2072-) to green ion (Cr3+). COD was measured at wavelength of 620nm.

\subsection{Determination of microalgal growth rate}

Using a spectrophotometer, the optical density of serially diluted sample $(0.1 \mathrm{ml})$ from each test tube was determined at $0 D 640 \mathrm{~nm}$. Growth rate per day was calculated by fitting the OD for each day into the exponential function: 
$\mathrm{GR}=\left(\ln \mathrm{ODt}-\ln \mathrm{OD}_{0}\right) / \mathrm{t}$

where $\ln \mathrm{OD}_{0}$ is the natural log of optical density at the initial day; lnODt is the natural log of optical density measured on day t.

\section{Results and discussion}

\subsection{Morphological/ microscopic characterization and Identification of Isolate}

After cultural examination and microscopy, the isolated algae were characteristic of Chlorella sp. as shown in Table 1.

Table 1 Morphological/ microscopic characteristics of isolates

\begin{tabular}{lllllll}
\hline Colony code & Colour & Edge & Elevation & Surface & shape & Probable organism \\
\hline TP-1 & Greenish & Smooth & Raised & Rough & globular & Chlorella sp \\
TP-2 & Greenish & Smooth & Raised & Rough & Spherical & Chlorella sp \\
TP-3 & Greenish & Smooth & Raised & Rough & spherical & Chlorella sp \\
\hline
\end{tabular}

\subsection{Microalgal growth rate}

The growth pattern (Fig.2 \& Fig. 3) obtained for Chlorella sp in sewage effluent showed that; 0 to 4 th day of cultivation marked the lag phase of the organism while exponential growth was observed from day 5-10. The stationary phase set in after the 10th day due to reduced nutrient availability followed by decline on day 14 and 15 . Similar pattern was observed in Bg-11 (control) except that the onset of exponential phase was a little bit prolonged due to lesser nutrient supply, followed by a rapid onset of stationary and decline phases.

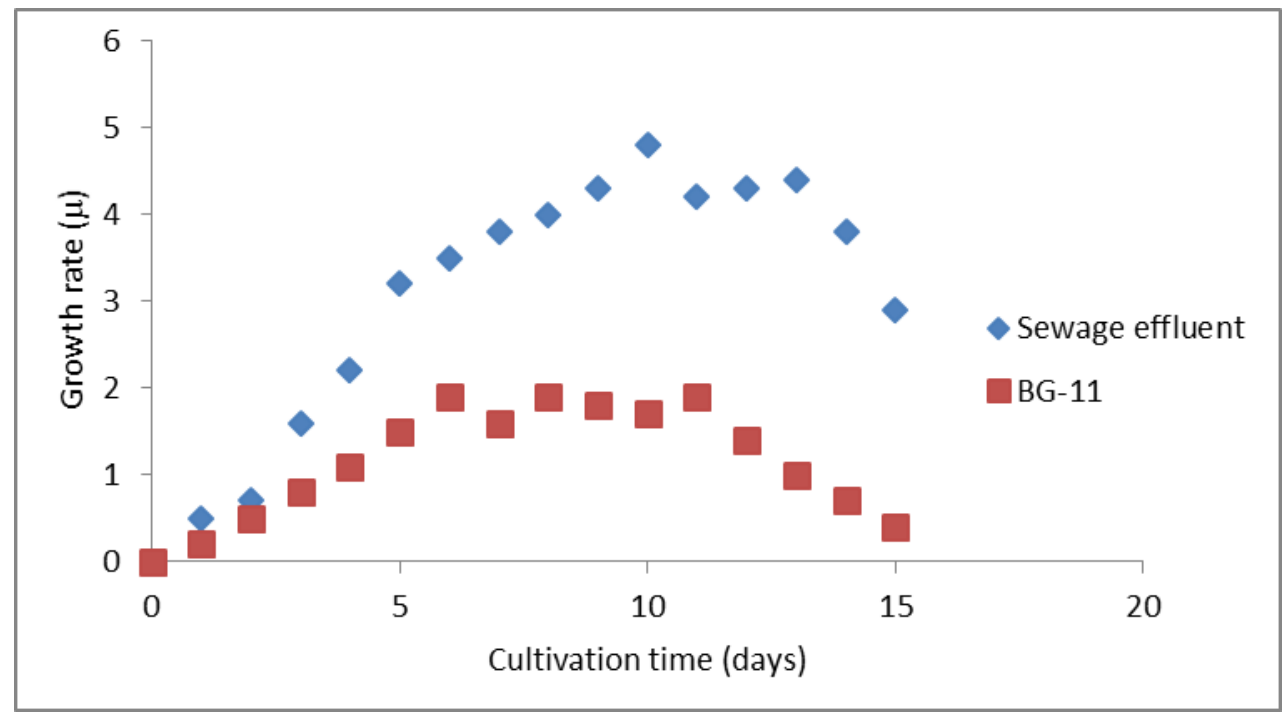

Figure 2 Growth curve of Chlorella sp. in sewage effluent and BG-11 (control) 

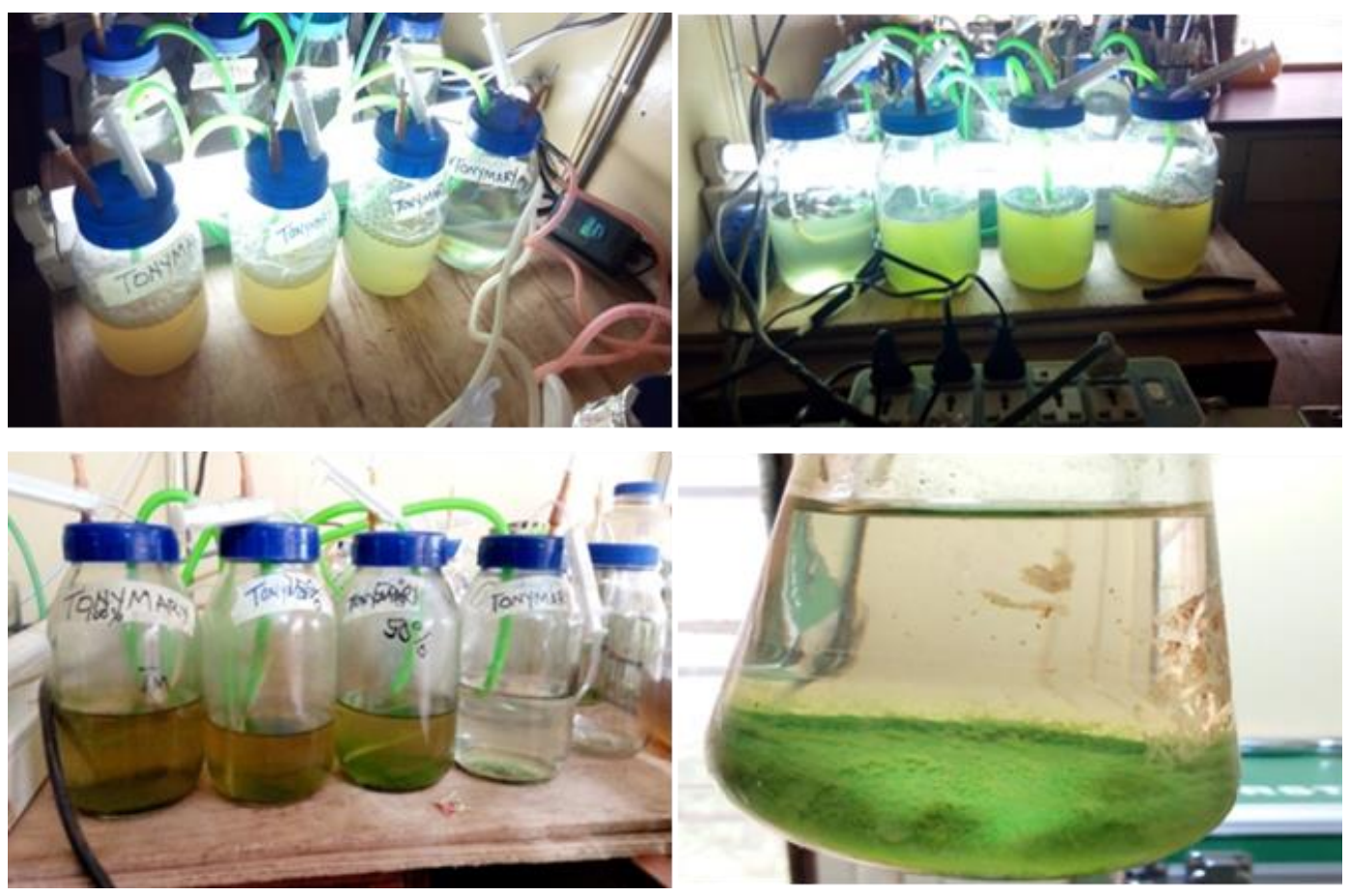

Figure 3 Showing from up-left; days 2, 5, 10 and 15 of microalgae cultivation. At day 15, microalgae have taken up all the nutrients especially the Total phosphorus content and soluble solids present in the sewage effluent broth.

\subsection{Estimation phosphorus uptake by Microalgae}

Chlorella sp. showed maximum reduction in phosphorus concentration (61.8\% removal) in day 12 of cultivation. This is attributable to the fact that the organism exhibited exponential growth at this period and hence phosphorus requirement for growth (with subsequent removal from sewage effluent) was at its peak.

Table 2 Uptake of phosphorus by Chlorella sp.

\begin{tabular}{lllll}
\hline \multirow{2}{*}{ Time (days) } & \multicolumn{3}{l}{ TWR(control) } & \multicolumn{3}{l}{ Chlorella spp } \\
\cline { 2 - 5 } & Initial conc(mg/L) & \% removal & Initial conc(mg/L) & \% removal \\
\cline { 2 - 5 } 0 & $11.0 \pm 0.2$ & 0 & $11.0 \pm 0.2$ & 0 \\
3 & $9.5 \pm 0.2$ & 13.6 & $9.6 \pm 0.05$ & 12.7 \\
6 & $8.0 \pm 0.1$ & 27.3 & $6.0 \pm 0.1$ & 45.5 \\
9 & $7.90 \pm 05$ & 28.2 & $4.2 \pm 0.01$ & 61.8 \\
12 & $8.3 \pm 0.4$ & 24.5 & $6.5 \pm 0.3$ & 40.9 \\
15 & $9.1 \pm 0.05$ & 17.3 & $7.9 \pm 0.4$ & 28.2 \\
\hline
\end{tabular}

\subsection{Removal of Biochemical Oxygen Demand}

As shown in Table 3, Chlorella sp was able to reduce BOD up to $92.8 \%$ of its initial concentration in the sewage effluent while only $39.8 \%$ removal was recorded for the control. This connotes that biodegradable organic matter in the medium were utilized by the organism during growth/metabolism. 
Table 3 Removal of BOD by Chlorella sp

\begin{tabular}{|c|c|c|c|c|c|c|c|}
\hline \multirow{2}{*}{$\begin{array}{l}\text { Cultivation } \\
\text { (days) }\end{array}$} & \multirow[t]{2}{*}{ time } & \multicolumn{3}{|c|}{ TWR (control) } & \multicolumn{3}{|c|}{ Chlorella sp } \\
\hline & & $\begin{array}{l}\text { Initial } \\
\text { (mg/L) }\end{array}$ & Conc. & \% removal & $\begin{array}{l}\text { Initial } \\
\text { (mg/L) }\end{array}$ & Conc. & $\begin{array}{l}\% \\
\text { removal }\end{array}$ \\
\hline 0 & & $119.2 \pm 0.8$ & & 0 & $119.2 \pm 0.8$ & & 0 \\
\hline 3 & & $113.2 \pm 0.5$ & & 5.0 & $98.1 \pm 0.02$ & & 17.7 \\
\hline 6 & & $78.3 \pm 0.09$ & & 34.3 & $29.0 \pm 0.09$ & & 75.7 \\
\hline 9 & & $71.7 \pm 0.09$ & & 39.8 & $8.6 \pm 0.1$ & & 92.8 \\
\hline 12 & & $92.4 \pm 1.4$ & & 22.5 & $42.6 \pm 0.6$ & & 64.3 \\
\hline 15 & & $101.9 \pm 0.1$ & & 14.5 & $60.1 \pm 0.1$ & & 59.1 \\
\hline
\end{tabular}

\subsection{Estimation of COD removal}

COD was more efficiently removed with increasing time. Percentage removal of 59.6 and 41.7 were obtained for Chlorella sp and control respectively (Table 4).

Table 4 Estimation of COD removal

\begin{tabular}{lllll}
\hline Time (days) & TWR(control) & \multicolumn{2}{l}{ Chlorella spp } \\
\cline { 2 - 5 } & Initial Conc. (mg/L) & \% removal & Initial Conc. (mg/L) & $\begin{array}{l}\text { \% } \\
\text { removal }\end{array}$ \\
\hline 0 & 240 & 0 & 240 & 0 \\
3 & 223 & 7 & 188 & 21.7 \\
6 & 218 & 9.2 & 165 & 31.3 \\
9 & 192 & 20 & 133 & 44.6 \\
12 & 179 & 25.4 & 109 & 54.6 \\
15 & 140 & 41.7 & 97 & 59.6 \\
\hline
\end{tabular}

Data are expressed as mean of three replicate \pm SD (standard deviation).

\subsection{Effects of temperature on BOD and COD removal}

It was observed that temperature had significant impact on the elimination of BOD and COD by Chlorella sp. The temperature of the experimental set up varied between $15^{\circ} \mathrm{C}$ to $35^{\circ} \mathrm{C}$ showed that the best removal efficiency ranged between $25-30^{\circ} \mathrm{C}$ for all the chemical parameters examined (Fig.4).

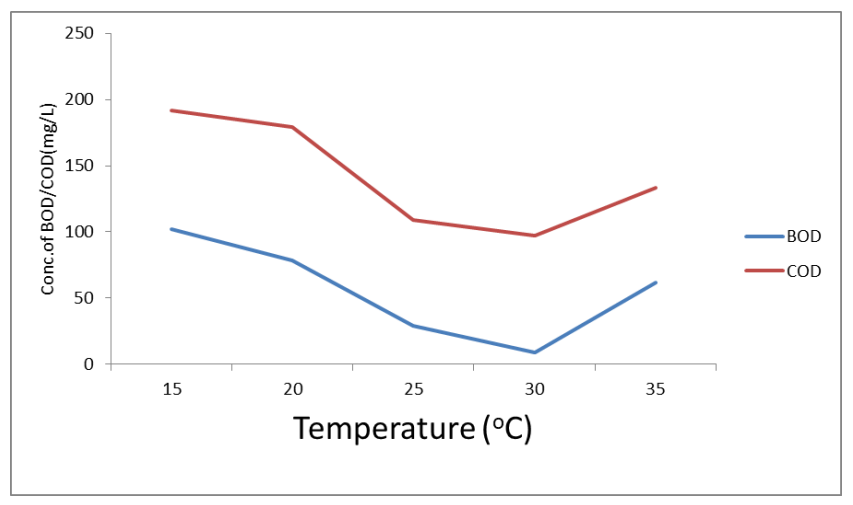

Figure 4 Changes in BOD/COD concentration with temperature

\subsection{Effects of temperature phosphorus removal}

As seen for BOD and COD removal, highest phosphorus removal by Chlorella sp. was recorded at $30^{\circ} \mathrm{C}$ (Fig. 5). 


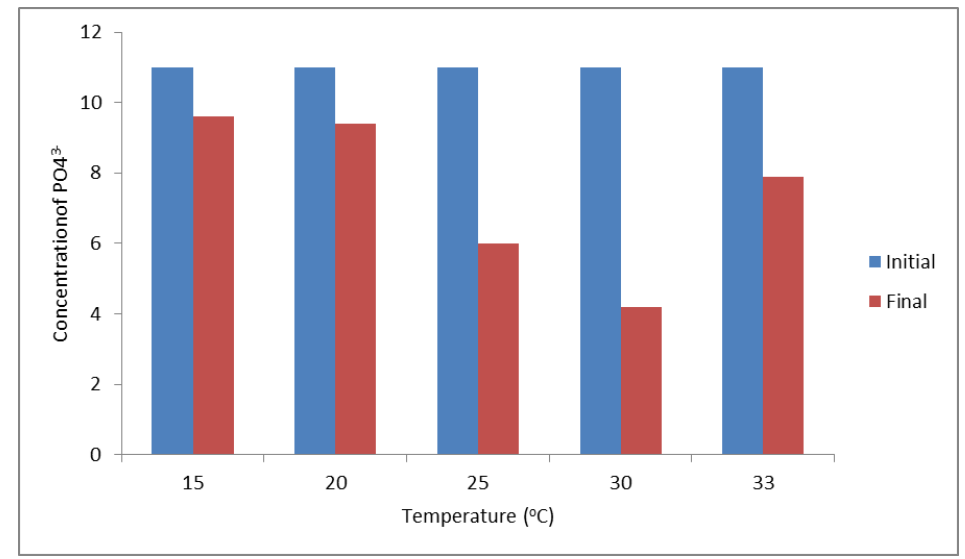

Figure 5 Concentration of $\mathrm{PO}^{3-}$ at varying temperatures

The removal of Phosphorus, BOD and COD from the effluent in this study showed strong dependence on factors including temperature, aeration, cultivation time and photoperiods. It was recorded that temperatures between 25 $30^{\circ} \mathrm{C}$ were optimum for the reduction/ elimination of these chemical parameters from wastewater. This shows there is a relationship between temperature and growth rate whereby growth rate tend to increase with increasing temperature of growth until it reaches a maximum value of $\left(30^{\circ} \mathrm{C}\right.$ in this case $)$ and then begin to decline. This implies that, beyond $30^{\circ} \mathrm{C}$, the activity of microorganism (Chlorella $\mathrm{sp}$ ) begins to decrease hence less BOD, COD and PO43-uptake. This corroborates a study by [16] where maximum removal of COD, BOD, nitrogen and phosphorus from industrial wastewater was obtained at $30^{\circ} \mathrm{C}$

Similarly, cultivation period (days) had significant effect on the removal efficiency of Chlorella sp. Peak activities were observed at the exponential phase in both sewage effluent and control. At this time, Chlorella sp had fully adapted to medium and rapidly utilizing its constituent for its growth and other metabolic activity, hence, the efficiency of nutrient removal is increased. This means phosphorus and some other oxidizable organic matter present in the effluent serve as nutrient for Chlorella sp growth. $[17,18]$ had previously reported optimum removal of chemical contaminants from wastewater at exponential phase of growth of Algal species. At the elapse of the experimental period, $61.8 \%$ and $28.2 \%$ phosphorus removal was recorded in test and control medium respectively. Chlorella sp is capable of taking up phosphorus as inorganic orthophosphate (PO43-) because it serves as a micro-nutrient essential for growth. Though satisfactory, this finding compared to studies by $[4,19,20]$ which reported up to $80.9 \%, 87 \%$ and $90 \%$ phosphorus removal by Chlorella sp is relatively low. The average percentage BOD reduction calculated for the present study is 92.8 $\%$ and $39.8 \%$ respectively for the test and control samples while COD gave $59.6 \%$ and $41.7 \%$ respectively. This implies Chlorella is more efficient in BOD removal compared to COD. This is probably due to high concentration of xenobiotic compounds elevating the COD of the wastewater which remains unaffected by microflora [21] or a pointer that sufficient oxygen needed to oxidize all organic material in the sewage effluent was not adequately supplied. From a study conducted by [22], they observed that aeration facilitated algal biomass due to enhanced photosynthetic activity of the algal, thereby releasing more oxygen for COD removal. Likewise, [4] recorded maximum reduction efficiencies of $90.8 \%$ and $80.1 \%$ by Chlorella sp after 20 days of incubation period.

\section{Conclusion}

This study showed that microalga (Chlorella sp.) can be cultivated in sewage effluents with appreciable removal of phosphorus, COD and BOD. To improve the efficiencies of this removal, physical factors such as temperature; cultivation periods and light intensity must be optimized. Hence, at optimal conditions, Chlorella sp. offers an excellent, cost effective and eco- friendly technology for the treatment of municipal and industrial wastewater.

\section{Compliance with ethical standards}

\section{Acknowledgments}

The Authors wish to appreciate Dr. V.N. Chigor and Mr. Anumudu, O.H. for the thorough supervision and assistance given to ensure the success of this project. 


\section{Disclosure of conflict of interest}

The authors declare no conflict of interests.

\section{References}

[1] Filippino KC, Mulholland MR and Bott CB. (2015). Phycoremediation strategies for rapid tertiary nutrient removal in a waste stream. Algal Research, 11, 125-133.

[2] Abdel-Raouf N, Al-Homaidan AA and Ibraheem IB. (2012). Microalgae and wastewater treatment. Saudi Journal of Biological Sciences, 19, 257-275.

[3] Marchello AE, Lombardi AT, Dellamano-Oliveira MJ and de-Souza CW. (2015). Microalgae population dynamics in photobioreactors with secondary sewage effluent as culture medium. Brazilian Journal of Microbiology, 46(1), 75-84.

[4] Hammouda 0, Abdel-Raouf N, Shaaban M and Kamal M. (2015). Treatment of Mixed Domestic-industrial Wastewater Using microalgae Chlorella sp. Journal of American Science, 11, 12.

[5] Travieso L, Benitez F, Sanchez E, Borja R, Martin A and Colmenarejo MF. (2006). Batch mixed culture of (Chlorella vulgaris) using settled and diluted piggery waste. Ecological Engineering Journal, 28, 158-165.

[6] Solovchenko A, Verschoor AM, Jablonowski ND and Nedbal L. (2016). Phosphorus from wastewater to crops: An alternative path involving microalgae. Biotechnology Advances, 34(5), 550-564.

[7] Gonçalves AL, Pires JC and Simões M. (2017). A review on the use of microalgal consortia for wastewater treatment. Algal Research, 24, 403-415.

[8] Wang C, Yu X, Lv H and Yang J. (2013). Nitrogen and phosphorus removal from municipal wastewater by the green alga chlorella sp. Journal of Environmental Biology, 34, 421-425.

[9] Hodaifa G, Martínez ME and Sánchez S. (2010). Influence of temperature on growth of Scenedesmusobliquus in diluted olive mill wastewater as culture medium. Engineering in Life Sciences, 10(3), 257-264.

[10] Sharma GK and Khan SA. (2013). Bioremediation of sewage wastewater using selective algae for manure production. International Journal of Environmental Engineering and Management, 4, 573-580.

[11] Shabudeen S, Ponnuswamy I and Madhavan S. (2013). Isolation and characterization of green Microalgae for carbon sequestration, wastewater treatment and bio-fuel production. International Journal of Bioscience and Biotechnology, 5, 2.

[12] Amengual-Morro C, Niell GM and Martínez-Taberner A. (2012). Phytoplankton as bioindicator for waste stabilization ponds. Journal of Environmental Management, 95, 571-576.

[13] Fathi AA, El-Shahed AM, Shoulkamy MA, Ibraheim HA and Abdel-Rahman OM. (2008). Response of Nile water phytoplankton to the toxicity Cobalt, Copper and Zinc. Research Journal of Environmental Toxicology, 2, 67-76.

[14] APHA (American Puplic Health Association) AWWA and WPCF (1981). Standard Methods for the Examination of Water and Wastewater. 15th edition, Washington, DC.

[15] HACH C. (2007). DR 2800 Spectrophotometer Manual, USA, 1-814.

[16] Azeez RA. (2010). A Study on The Effect Of Temperature on The Treatment of Industrial Wastewater Using Chlorella Vulgaris Alga . Engineering and Technology Journal, 28, 4.

[17] Wang L, Min M, Li Y, Chen P, Chen Y, Liu Y, Wang Y and Ruan R. (2009). Cultivation of Green Algae Chlorella sp. in Different Wastewaters from Municipal Wastewater Treatment Plant. Applied Biochemistry and Biotechnology.

[18] Sharma R, Tiwari AK, Kumar GS and Lamba BY. (2015). Cost effective and economic method for cultivation of Chlorella pyrenoidosa for the simultaneous treatment of biogas digester wastewater and biogas production. International Journal of Pharma Sciences and Research, 6(2), 318-321.

[19] Li Y, Chen YF, Chen P, Min M, Zhou W, Martinez B, Zhu J and Ruan R. (2011). Characterization of a microalga Chlorella sp. well adapted to highly concentrated municipal wastewater for nutrient removal and biodiesel production. Bioresource Technology, 102(8), 5138-5144.

[20] Velan M and Saravanane R. (2013). CO2 Sequestration and Treatment of Municipal Sewage by Micro Algae. International Journal of Innovative Technology and Exploring Engineering, 2(5), 307- 310. 
[21] Garg SK and Tripathi M. (2013). Process parameters for decolourization and biodegradation of orange II (Acid Orange 7) in dye-simulated minimal salt medium and subsequent textile effluent treatment by Bacillus cereus (MTCC 9777) RMLAU1. Environmental monitoring and assessment, 185(11), 8909-8923.

[22] Mata TM, Melo AC, Simões M and Caetano NS. (2012). Parametric study of a brewery effluent treatment by microalgae Scenedesmusobliquus. Bioresource Technology, 107, 151-158.

\section{How to cite this article}

Anumudu OH, Akaniro IR, Ezeh CC, Koledowo AK, Oweredaba CI, Ofonegbu MN and Kwekowe PC. (2019). Determination of uptake rate of phosphorus and changes in COD and BOD during photoautotrophic cultivation of microalgae in sewage effluent. World Journal of Advanced Research and Reviews, 4(2), 01-09. 